\title{
Indústria 4.0 e a Qualidade da Informação
}

\author{
José Antônio Esmerio Mazzaferro ${ }^{1}$
}

1 Universidade Federal do Rio Grande do Sul - UFRGS, Laboratório de Soldagem \& Técnicas Conexas - LS\&TC, Porto Alegre, RS, Brasil.

E-mail: mazza@ufrgs.br (JAEM)
Este é um artigo publicado em acesso aberto (Open Access) sob a licença Creative Commons Attribution Non-Commercial, que permite uso, distribuição e reprodução em qualquer meio, sem restriçōes desde que sem fins comerciais e que 0 trabalho original seja corretamente citado.
Atualmente, a indústria está atravessando mais uma revolução que pode alterar sensivelmente os sistemas de produção. $\mathrm{Na}$ área da soldagem, a chamada Indústria 4.0 se traduz na existência de fontes inteligentes, uso extensivo de robótica, sistemas confiáveis de processamento e armazenamento de dados, além de monitoramento e controle das operações de soldagem em tempo real. Tudo isso integrado visando utilizar adequadamente recursos e procedimentos que permitam aumentar a produtividade e garantir a qualidade das juntas obtidas.

Nesses tempos em que a "inteligência" dos equipamentos e sistemas parece fazer a clássica definição de soldagem tida como um "misto de arte e técnica" parecer desatualizada por pender descaradamente para o lado da tecnologia, é que a importância de instrumentos de disseminação do conhecimento como a Revista Soldagem \& Inspeção se torna ainda maior.

O que não se pode esquecer é que por trás de toda essa tecnologia existem anos de pesquisa e desenvolvimento. Toda a automatização, eletrônica embarcada, desenvolvimento de softwares e sistemas dedicados só se traduz em avanço sustentável que justifique o nome de revolução se os tão propalados resultados puderem ser sistematicamente obtidos. Isso só ocorrerá se continuarmos aproveitando cada avanço revelado na forma de resultado de pesquisa, disponível, por exemplo, nos periódicos de comprovada qualidade da área. É aí que reside a importância de alimentarmos e usufruirmos desse autêntico canal de disseminação do conhecimento técnico e científico que é a Revista Soldagem \& Inspeção. A adequada utilização do conhecimento pode fazer a diferença entre uma revolução tecnológica bem-sucedida e a monumental capacidade de multiplicação de um erro com auxílio da mais avançada tecnologia disponível. A disponibilização e uso da informação só é produtiva quando essa informação provém de fontes confiáveis. Essa é apenas uma das funções de veículos como o que todos nós, editores, revisores e autores de artigos submetidos à Revista Soldagem \& Inspeção, temos a satisfação de integrar e ajudar a construir a cada nova edição. A análise feita pelos professores Ana Sofia C.M d'Oliveira e Américo Scotti [1] sobre o posicionamento da Revista Soldagem \& Inspeção nos cenários Nacional e Internacional sob a luz dos índices Scimago/Scopus [2] (SJR) e Clarivate/Thomsom Reuters InCites [3] (JCR) bem demonstra seu lugar de destaque entre as revistas dedicadas à soldagem no mundo.

Neste contexto, foi com surpresa e um misto de apreensão e satisfação que recebi o convite para ocupar a função de Editor-Chefe da Revista Soldagem \& Inspeção. Pretendo desempenhar essa atividade sendo movido pelo mesmo entusiasmo e orgulho que senti ao ter meu primeiro artigo publicado pela então Revista Soldagem \& Materiais no longínquo ano de 1992. Já nesses primeiros meses foi possível comprovar a enorme responsabilidade que é estar à frente da Revista S\&I e o tamanho dos desafios envolvidos. Como muito bem descreveu o professor Ronaldo Paranhos [4], apesar dos sensíveis avanços alcançados, como adoção do formato de periódico científico, indexação em importantes bases de dados, aumento da internacionalização e inserção na Coleção SciELO, ainda há outros tantos avanços a perseguir. Um fato que merece registro é o grande aumento na colaboração internacional avaliado com base na quantidade de artigos produzidos por autores de mais de um país no último ano de avaliação [2].

Nesta edição, além do Brasil há artigos de autores da Colômbia, Iran, México e Portugal, abordando processos e técnicas de soldagem, simulação numérica e efeito da soldagem 
sobre as propriedades das juntas obtidas. Tenho certeza de que os resultados das pesquisas/desenvolvimentos aqui apresentados hão de servir de inspiração para outros tantos trabalhos originais, além de contribuir para o universo de informações de qualidade disponíveis para aplicações que ajudarão a fazer a Indústria 4.0 uma revolução baseada no conhecimento.

\section{Referências}

[1] d'Oliveira ASCM, Scotti A. Uma reflexão sobre a Revista Soldagem \& Inspeção no contexto dos índices de avaliação internacionais e brasileiro. Soldagem e Inspeção. 2015;20(2):135-136. http:// dx.doi.org/10.1590/0104-9224/SI2002.01.

[2] SCImago Journal \& Country Rank [página da internet]. Spain: ScimagoLab; 2017. [acesso em 15 maio 2018]. Disponível em http://www.scimagojr.com/journalsearch.php.

[3] InCites. InCites Journal Citation Reports [página da internet]. 2018 [acesso em 15 maio 2018]. Disponível em http://jcr-incites-thomsonreuters.ez45.periodicos.capes. gov.br.

[4] Paranhos R. Marcos e Desafios para S\&I. Soldagem e Inspeção. 2016;21(3):251-252. http://dx.doi.org/10.1590/0104-9224/ SI2103.01. 